\title{
Magnesium Alloys as Promising Degradable Implant Materials in Orthopaedic Research
}

\author{
Janin Reifenrath ${ }^{1}$, Dirk Bormann ${ }^{2}$ and Andrea Meyer-Lindenberg ${ }^{1}$ \\ ${ }^{1}$ Small Animal Clinic, University of Veterinary Medicine Hannover \\ 2Institute for Material Science, University of Hannover
}

Germany

\section{Introduction}

Magnesium alloys as degradable implant materials in orthopaedic research received a lot of interest in recent years (Witte et al., 2007a; Xu et al., 2008; Zhang et al., 2010). The application of resorbable implant material avoids an implant removal surgery and therewith helps to diminish the costs and the burden for the patient. In comparison to other degradable implant materials like polymers, magnesium alloys excel in higher tensile and compressive strength and the young's modulus is near to cortical bone (Hofmann, 1995; Staiger et al., 2006; Kaese, 2002). Another advantage that leads to the choice of magnesium alloys as implant material is the fact, that magnesium is a natural component of the body and furthermore has many important functions within the body (Hartwig, 2001). Magnesium is tested as non-allergenic (Witte et al., 2007a) and due to several studies it is assumed, that it stimulates new bone formation in vitro and in vivo (Revell et al., 2004; Zreitqat et al., 2002; Witte et al., 2007b).

For the application as orthopedic implant material in weight bearing bones, only magnesium alloys with a slow corrosion rate are useful. A high corrosion rate results in gas formation, a too fast loss of mechanical stability and a considerably higher bone remodelling activity (Thomann et al., 2009; Krause et al., 2010). Beside to different coating facilities (Witte et al., 2009; Zhang et al., 2010) and surface treatments (von der Höh et al., 2006; Hänzi et al., 2008), in particular the alloying of aluminium, lithium, rare earth metals or calcium decrease the corrosion rate in vitro and in vivo (Kaese, 2002; Staiger, 2006; Hänzi et al., 2008; Krause et al., 2010; Thomann et al., 2009). However, in vivo and in vitro corrosion rates can be quite different (Witte et al., 2006; Zhang et al., 2010), which makes it more difficult to develop and adapt magnesium alloys for biomedical use.

In order to investigate if the chosen magnesium-alloys are suitable for the use in orthopedic applications, in vivo-studies in rabbit tibiae were conducted. Therefor the selected and in vitro examined magnesium alloys LAE442, WE43, MgCa0.8, AX30, ZEK100 were implanted into the rabbit tibia and examined with regard to the mechanical stability, the in vivo corrosion rate and the biocompatibility.

For the in vivo investigation of the implant materials, the rabbit was used as established animal model for orthopaedic applications (Pearce, 2007). All animal experiments were conducted under an ethic committee approved protocol in accordance with German federal welfare legislation. Five rabbits were used for each group. Extruded pins with $2.5 \mathrm{~mm}$ in 
diameter and $25 \mathrm{~mm}$ length were implanted into both tibiae (Fig.1a). Four tibiae remained without implant and served as control.

The used alloys contained adjacent to magnesium the elements lithium, aluminium and a rare earth composition metal (LAE442), yttrium and a rare earth composition metal (WE43), calcium (MgCa0.8), aluminium and calcium (AX30) or zinc, a rare earth composition metal and zirconium (ZEK100). The numbers describe the percentage of the alloying elements adjacent to magnesium, in accordance with the ASTM-standard. At the time of surgery, all rabbits were older than six months and hence adult. In general anaesthesia, a hole was drilled into the tibial plateau and the implant was inserted. The detailed operation procedure is described elsewhere (Thomann et al., 2009). Radiographs of two planes were taken immediately after surgery (Fig. 1b).

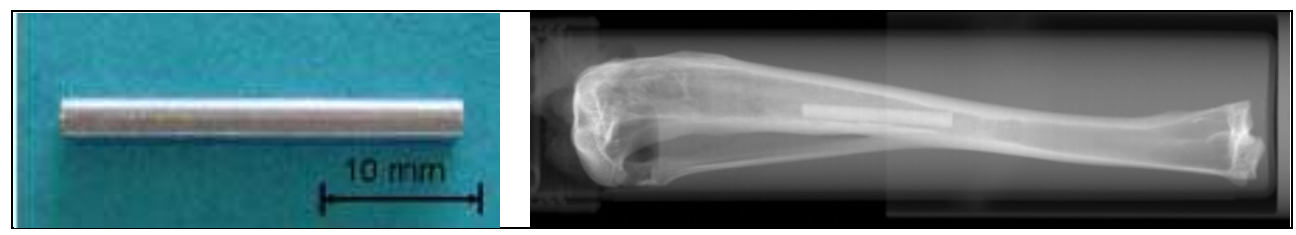

Fig. 1. Implant material and implant location: extruded magnesium pin (a) and radiographical picture of the implant location in the rabbit tibia (b)

Postoperative observation periods with daily clinical and weekly radiographical examinations of three, six and in some material groups (LAE442 and $\mathrm{MgCa} 0.8$ ) twelve months were studied. During the observation period, intravital fluorescent labelling was performed (Tab. 1) and evaluated in the LAE442 group, as rare-earth containing alloy, and in the $\mathrm{MgCa} 0.8$ group, as calcium containing alloy, as well as in the controls. The fluorochromes calcein green (Calcein, Fa. Sigma Aldrich, Germany), calcein blue (Methylumbiliferone, Fa. Sigma Aldrich, Germany), tetracycline (Ursocyclin, Serumwerk Bernburg, Germany) and Xylenolorange (Fa. Sigma Aldrich, Germany) were used (Rahn et al., 1980).

\begin{tabular}{|ccccc|}
\hline $\begin{array}{c}\text { Time } \\
\text { period }\end{array}$ & $\begin{array}{c}\text { first staining } \\
\text { (days) }\end{array}$ & fluorochrome & $\begin{array}{c}\text { second staining } \\
\text { (days) }\end{array}$ & fluorochrome \\
\hline 1 & 3 and 5 & calcein green & 30 and 33 & xylenolorange \\
\hline 2 & 30 and 33 & xylenolorange & 60 and 63 & calceinblue \\
\hline 3 & 60 and 63 & calceinblue & 90 and 93 & tetracycline \\
\hline 4 & 90 and 93 & tetracycline & 120 and 123 & calceinblue \\
\hline 5 & 120 and 123 & calceinblue & 150 and 153 & xylenolorange \\
\hline 6 & 150 and 153 & xylenolorange & 180 and 183 & calceingreen \\
\hline
\end{tabular}

Table 1. Time points and fluorochromes of intravital fluorescent labelling for the measurement of the bone remodelling and the calculation of the MAR.

At the end of the observation period, the rabbits were euthanized and the tibiae removed. In the left tibiae, the implants were taken out for measurement of weight reduction, scanning electron microscopy (SEM) and evaluation of the mechanical stability with three point bending test. To determine the decrease of weight, the adhering organic material was 
removed into a dipping bath of $40 \%$ hydrofluoric acid for five minutes, cleaned in distilled water and ethyl alcohol for $10 \mathrm{sec}$ and air dried. SEM allowed an examination of the surface of the implant and was done at a LEO1455VP (Fa. Zeiss, Germany) with a Rutherford BackScattered Detector and a 30-fold magnification. Three point bending was performed using a $10-\mathrm{kN}$ load cell to measure the maximal applied force (Krause et al., 2010). Additionally to all explanted pins, three pins of each alloy were tested in their initial state. The right tibiae were left as the bone-implant-compound for $\mu$-computed tomographical and histological examinations. Four tibiae without implant material served as control for the $\mu$-computed tomographical and the histological analysis.

In $\mu$-computed tomography, samples were analysed with a slice sickness of $36 \mu \mathrm{m}$ and a scanning time of 1s. An evaluation of endosteal and periosteal bone remodeling as well as bone adhesion on the implant material was done with a semi quantitative scoring system (Krause et al., 2010; Thomann et al., 2009) (Fig. 2).

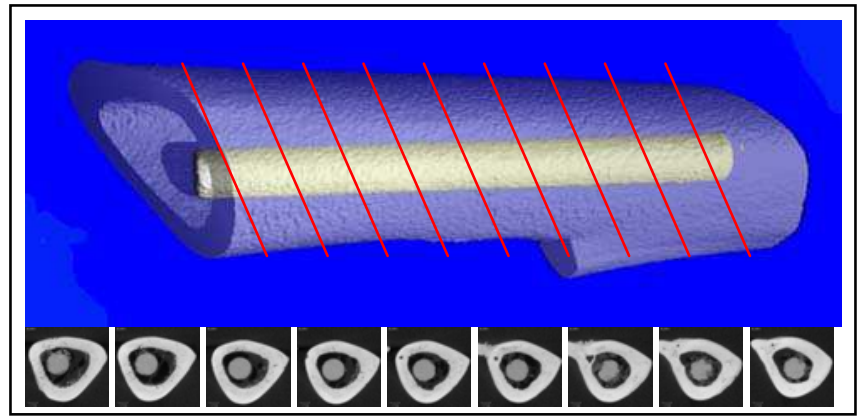

Fig. 2. Evaluation of the implant degradation and the bone morphology with $\mu$-computed tomography (schematic picture): nine cross sectional slices of each tibia were evaluated

For histological analysis, the samples were dehydrated and embedded in Glycolmethacrylat (Technovit 7200, Kulzer, Germany). Histological slices were prepared according to the cutting and grinding technique (Donath \& Breuner, 1982). With this technique, there was no need to decalcify the bone material, which could lead to a loss of the degradable magnesium alloy and fluorochromes prior to evaluation. Measurement of the bone remodelling and calculation of the MAR (MgCa0.8 and LAE442) was done. Therefore the distance between the different flurochrome labels, which where administered at different time points, were measured at twelve defined points within each section (Fig. 3). A calculation of the mineral apposition rate (MAR) was possible with the following equation (Parfitt et al., 1987):

$\operatorname{MAR}(\mu \mathrm{m} / \mathrm{d})=$ distance fluorescent bands $(\mu \mathrm{m}) /$ time period between labelling $(\mathrm{d})$

Evaluation of the bone structure, the bone remodelling and the bone implant interface was done with toluidine blue as standard staining method for bone material. Bone morphology and cells were assessed with a semi quantitative scoring system (Tab. 2).

Additional to the standard staining method, TRAP-staining was used for osteoclast detection (Schäfer et al., unpublished data). As calcium-containing alloy, $\mathrm{MgCa} 0.8$ was examined, as examples for rare earth containing alloys, WE43 and LAE442 were stained and evaluated. For statistical analysis ANOVA and t-test were performed. 


\begin{tabular}{|c|c|c|}
\hline Parameter & Score & Interpretation \\
\hline \multirow{2}{*}{$\begin{array}{l}\text { overall impression of bone } \\
\text { structure (BS) }\end{array}$} & 0 & smooth \\
\hline & 1 & irregular \\
\hline \multirow[t]{4}{*}{ bone cavities (BC) } & 0 & $\leq 3$ osteonlike cavities \\
\hline & 1 & 4 to 6 osteonlike cavities or $\leq 10$ smaller \\
\hline & 2 & 7 to 10 osteonlike cavities or 11 to 20 smaller \\
\hline & 3 & $\begin{array}{l}\geq 11 \text { osteonlike cavities or } 21 \text { smaller or } \geq 3 \\
\text { doubleosteonlike cavities }\end{array}$ \\
\hline \multirow[t]{4}{*}{ periosteal remodelling $(\mathrm{pR})$} & 0 & no \\
\hline & 1 & $\geq 1 / 4$ periosteal bone, 1 osteon thick \\
\hline & 2 & $\geq 1 / 4$ periosteal, 2 osteon thick \\
\hline & 3 & $\geq 1 / 4$ periosteal bone, 3 osteon thick \\
\hline \multirow[t]{4}{*}{ endosteal remodelling (eR) } & 0 & no \\
\hline & 1 & $\geq 1 / 4$ endosteal bone, 1 osteon thick \\
\hline & 2 & $\geq 1 / 4$ endosteal bone, 2 osteon thick \\
\hline & 3 & $\geq 1 / 4$ endosteal bone, 3 osteon thick \\
\hline \multirow{2}{*}{$\begin{array}{l}\text { periosteal apposition } \\
(\mathrm{pA})\end{array}$} & 0 & no \\
\hline & 1 & yes \\
\hline \multirow{2}{*}{$\begin{array}{l}\text { periimplant bone formation } \\
\text { (PIF) }\end{array}$} & 0 & no \\
\hline & 1 & yes \\
\hline \multirow[t]{4}{*}{ periimplant fibrosis } & 0 & no \\
\hline & 1 & $\leq 25 \%$ implantsurface \\
\hline & 2 & 26-50\% implantsurface \\
\hline & 3 & $\geq 51 \%$ implantsurface \\
\hline \multirow{4}{*}{$\begin{array}{l}\text { lymphoplasmacellular } \\
\text { reaction (Lym) }\end{array}$} & 0 & $<30$ cells per section \\
\hline & 1 & $30-50$ cells per section \\
\hline & 2 & $51-100$ per section \\
\hline & 3 & > 100 cells per section \\
\hline \multirow[t]{3}{*}{ Macrophages (Mph) } & 0 & $<3$ cells per section \\
\hline & 1 & 3- 20 cells per section \\
\hline & 2 & $>20$ cells per section \\
\hline \multirow[t]{3}{*}{ giant cells (GC) } & 1 & no \\
\hline & 2 & 1-5 cells per section \\
\hline & 3 & $>10$ cells per section \\
\hline \multirow[t]{2}{*}{ gas bubbles } & 0 & no \\
\hline & 1 & yes \\
\hline
\end{tabular}

Table 2. Scoring system for the evaluation of histological sections, staining toluidine blue 


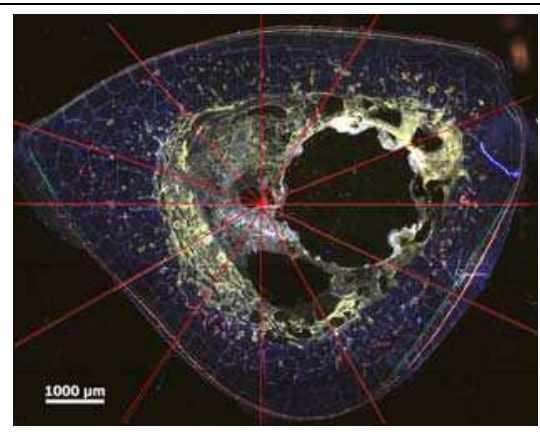

(a)

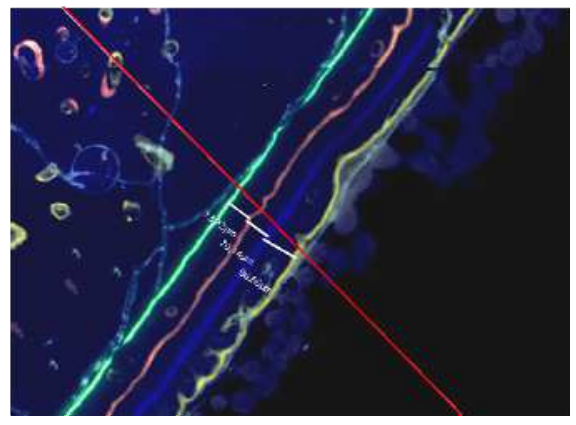

(b)

Fig. 3. Evaluation of the fluorescent labelling with measurement of the distances between the different flourochrome bands (observation time three months); 12 measurement lines per section (a) and measurement of the distance between fluorescent bands (b).

\section{Results}

Clinically, all tested materials were tolerated well and gas formation could not be detected. For all implants weight loss, according with the degree of degradation (Xu et al., 2008) and a decrease of mechanical stability could be found during in vivo observation periods of three, six (all implant groups) and twelve months (LAE442 and $\mathrm{MgCa} 0.8$ ). $\mathrm{MgCa} 0.8$ and WE43 showed highest weight losses with a mean value (MV) of $61.4 \%$ (MgCa0.8) and $66.4 \%$ (WE43) of their initial weights after six months in comparison to LAE442 (MV 75.3\%), ZEK100 (MV 76.1) and AX30 (79.8) which showed less weight reduction (Fig. 4a). After 12 months MgCa0.8 was highly degraded and the residual implant material showed only $33.0 \%$ of the initial weight. LAE442 corroded slower, ending up with a weight of $52.9 \%$.

In the three point bending tests, the maximal applied force (Fmax $[\mathrm{N}])$, which indicates the residual implant strength, decreased faster in the calcium containing than in the rare-earth containing alloys. After six months, the maximal force of $\mathrm{MgCa} 0.8$ was measured with $29.6 \%$ of the initial value $(178.7 \pm 84.6 \mathrm{~N})$ and AX30 showed similar results with $29.7 \%$ of the

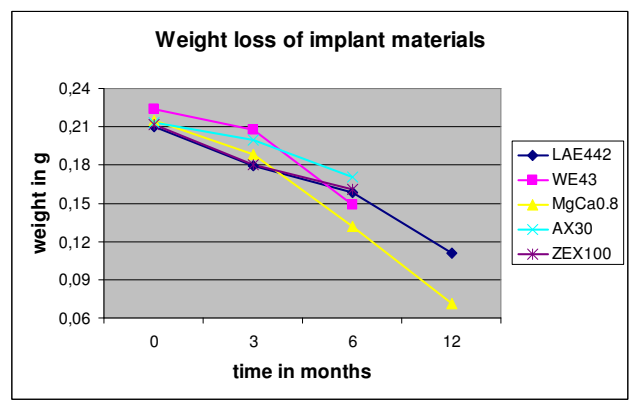

(a)

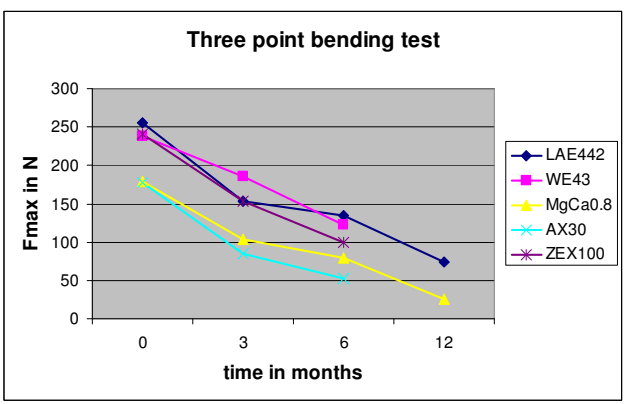

(b)

Fig. 4. Weight loss (a) and mechanical stability (b) of the different implant materials after three and six (all materials) and twelve months (LAE442 and MgCa0.8). 
initial value $(177.4 \pm 16.4 \mathrm{~N})$. The rare earth containing alloys retained $41.3 \%$ (ZEK100, initial value $240.8 \pm 2.4 \mathrm{~N}$ ), $51.3 \%$ (WE43, initial value $238.1 \pm 21.68 \mathrm{~N}$ ), and $52.7 \%$ (LAE442, initial value $255.7 \pm 5.7 \mathrm{~N}$ ) of their initial strength.

LAE442 decreased to a level of $28.7 \%$ even after an observation period of 12 months. It could be shown, that weight reduction as sign of degradation and loss of mechanical stability in vivo do not necessarily correspond in the examined degradable magnesium alloys. The corrosion morphology of the different alloys appeared quite different. After three months all implant materials preserved their cylindrical shape with corrosion layers of different extend on the implant surface. After six months implantation time the corrosion process at the implant surfaces proceeded. With the exception of ZEK100, all implant materials still showed their cylindrical shape. ZEK100 showed cleft surfaces and losses of implant material in greater extend than in the other groups. The surfaces of MgCa0.8 (Fig 5a), AX30 and ZEK100 were characterized by pitting corrosion. WE43 showed soil-like ablations on the surface (Fig 5b) and LAE442 homogeneous fissured corrosion (Fig. 5c). After an implantation period of twelve months (LAE442 and MgCa0.8), MgCa0.8 was highly degraded. Only one implanted pin could be removed completely. It showed deep pits of corrosion. The other implants could be taken out in sections. In contrast, in the LAE442 group, all implants remained cylindrical to a large extend after an implantation period of six and even after an implantation period of twelve months. Uniform fissure corrosion could be observed.

Bone reactions as sign of biocompatibility were less in the groups with the slower and more uniform degrading implant materials, particularly in the LAE442 group (Fig. 6).

In $\mu$-computed tomography, WE43 showed inhomogeneous implant degradation and a gradual loss of the bone structure. Trabecular new bone formation could be found in the majority of $\mu$-computed tomography slices of the bones around the implant. In the MgCa0.8 groups, after six months, bone adhesion at the implant material could be detected only sporadically. After twelve months $55 \%$ of the evaluated slices showed bone-implant contact of different degree. Some slices showed trabecular bone formation other partly or full ring bone contact around the implant material.

In the LAE442 group after six months $35 \%$ of the evaluated slices showed trabecular boneimplant contact, after twelve months $89 \%$ of the evaluated slices showed endosteal new bone formation and $53 \%$ trabecular bone-implant contact.

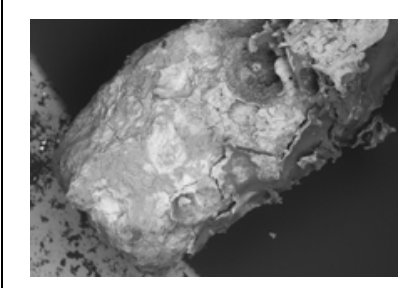

(a)

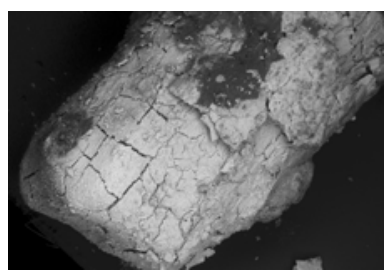

(b)

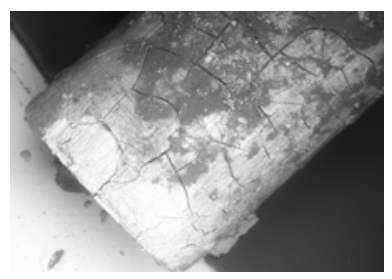

(c)

Fig. 5. Comparison of the surface morphology of the magnesium alloys MgCa0.8 (a), WE43 (b) and LAE442 (c) after 6 months postoperative observation period (REM, magnification 30x). 


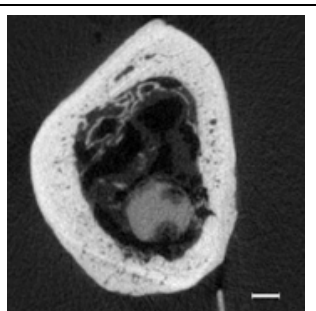

(a)

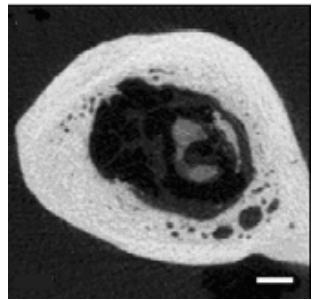

(b)

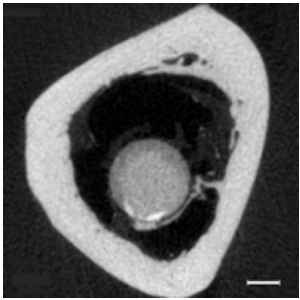

(c)

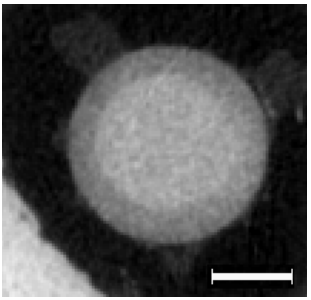

(d)

Fig. 6. $\mu$-computed tomographical picture of the fast degrading alloys AX30 (a), 6 months postoperatively and $\mathrm{MgCa} 0,8(\mathrm{~b}), 12$ months postoperatively with bone reactions and a slow degrading alloy LAE442 (c), 12 months postoperatively with endosteal new bone formation and trabecular bone-implant contact, loss of implant density as sign for implant corrosion (d), white bar $=1 \mathrm{~cm}$

In the histological examination polychrome sequence labelling was evaluated. In comparison to the control tibiae, the examined groups with magnesium implants showed an increased bone remodeling with a higher MAR. Especially in the first month the MAR was with $4.29 \mu \mathrm{m} / \mathrm{d}$ in the MgCa0.8 group and with $3.36 \mu \mathrm{m} / \mathrm{d}$ in the LAE442 group higher than in the control group without implant material (MAR $0.87 \mu \mathrm{m} / \mathrm{d}$ ). During the observation period, a decrease of MAR in the magnesium groups could be observed (Fig. 7).

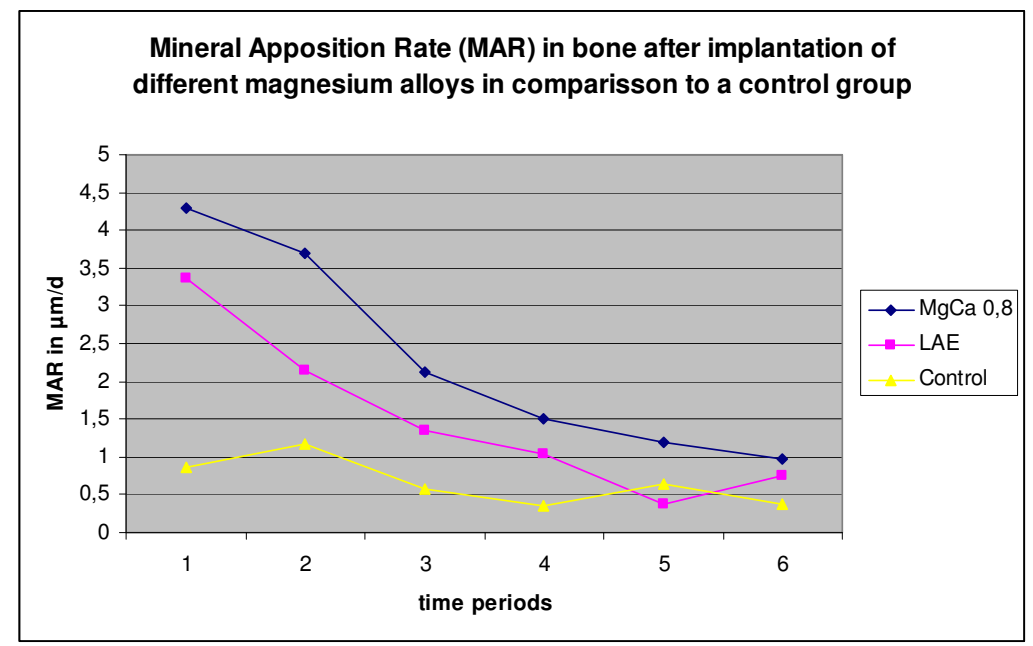

Fig. 7. MAR in the bone during the observation period of 6 months after the implantation of different magnesium alloys in comparison to control tibiae without implants.

Additionally to fluorescent labelling, the conventional histological toluidine blue staining was evaluated (Fig. 8 a-c) and after six months an irregular bone structure (Score value 1) could be observed in all examined material groups which, in the two longer observed groups, decreased with the increasing observation time. In the LAE442 group, the score value was reduced from 0.80 after six months to 0.00 after twelve months and in the 
$\mathrm{MgCa} 0.8$ group in the same period from a score value of 1.00 to 0.47 (SD 0.52). Different degrees of periosteal and endosteal remodelling were detected in all examined material groups (Tab. 3). Fibrous tissue covered less than $25 \%$ of the implant surface in all examined groups. For macrophages a score value of 1 could be observed after six months in all material groups as well as giant cells. In the $\mathrm{MgCa} 0.8$ group the macrophages and giant cells decreased by trend to a score of 0.8 (SD 0.41) and 0.87 (SD 0.64) after twelve months, in the LAE442 group a slight increase was found for macrophages (MV 1.17, SD 0.39) and giant cells (MV 1.08, SD 0.51). Histologically visible gas bubbles were found in all material groups after all observation periods (Tab. 3).

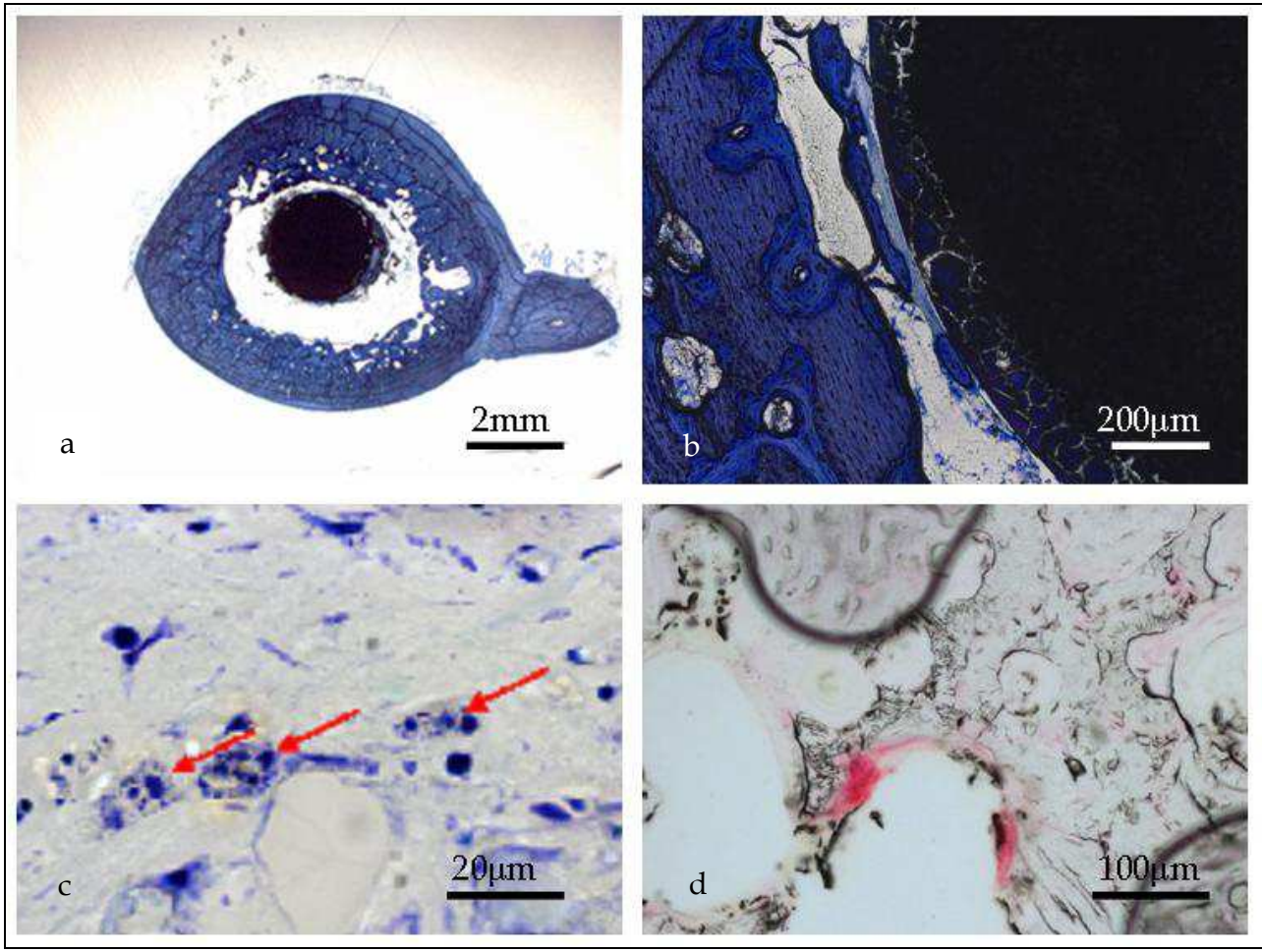

Fig. 8. WE 6 months (a) with an irregular bone structure with remaining implant material in the bone cavity; $\mathrm{MgCa} 0.812$ months $(\mathrm{b}, \mathrm{c})$, trabecular bone structures at the implant surface (b) and macrophages (red arrows) in the bone cavity (c), staining toluidine blue (a-c); TRAPstaining for osteoclast detection (osteoclasts $=$ red areas)

TRAP-staining was used additionally in the MgCa0.8, the WE43 and the LAE442 groups after three and six, and in the MgCa0.8 and in the LAE442 groups after twelve months to evaluate quantitative data measurement for bone remodeling activity (Fig. 9)

In the calcium-containing alloy $\mathrm{MgCa} 0.8$ more osteoclasts could be found in all time groups, but the differences between the time and material groups after three and six months were not significant. After twelve months implantation duration the total and cortical osteoclast number was significant lower $(\mathrm{p} \leq 0.001)$ in the LAE442 group than in the $\mathrm{MgCa} 0.8$ group. 


\begin{tabular}{lcccccccccccc}
\hline & & BS & BC & pR & eR & pA & PIF & Fibrosis & Lym & Mph & GC & bubbles \\
\hline WE43 & MV & 1,00 & 2,90 & 1,50 & 3,00 & 0,00 & 0,60 & 0,70 & 0,00 & 1,00 & 1,00 & 1,00 \\
\cline { 2 - 12 } 6 months & SD & 0,00 & 0,32 & 1,35 & 0,00 & 0,00 & 0,52 & 0,82 & 0,00 & 0,00 & 0,00 & 0,00 \\
\hline MgCa0.8 & MV & 1,00 & 2,30 & 2,40 & 2,80 & 0,00 & 0,80 & 0,90 & 0,00 & 1,00 & 1,00 & 1,00 \\
\cline { 2 - 12 } 6 months & SD & 0,00 & 0,82 & 0,70 & 0,42 & 0,00 & 0,42 & 0,99 & 0,00 & 0,00 & 0,00 & 0,00 \\
\hline LAE442 & MV & 0,80 & 2,10 & 1,00 & 2,30 & 0,10 & 1,00 & 0,20 & 0,20 & 1,00 & 1,00 & 1,00 \\
\cline { 2 - 11 } months & SD & 0,42 & 0,74 & 1,15 & 0,82 & 0,32 & 0,00 & 0,42 & 0,42 & 0,00 & 0,00 & 0,00 \\
\hline MgCa0.8 & MV & 0,47 & 0,73 & 1,93 & 1,13 & 0,00 & 0,60 & 0,00 & 0,00 & 0,80 & 0,87 & 1,00 \\
\cline { 2 - 10 } 12 months & SD & 0,52 & 1,03 & 1,10 & 0,35 & 0,00 & 0,51 & 0,00 & 0,00 & 0,41 & 0,64 & 0,00 \\
\hline LAE442 & MV & 0,00 & 0,00 & 1,83 & 0,50 & 0,00 & 0,17 & 0,25 & 0,08 & 1,17 & 1,08 & 1,00 \\
12 months & SD & 0,00 & 0,00 & 0,72 & 0,90 & 0,00 & 0,39 & 0,45 & 0,29 & 0,39 & 0,51 & 0,00 \\
\hline
\end{tabular}

Table 3. Score values of histological sections in the different material groups after 6 and 12 months implantation time, staining toluidine blue, Abbreviations are described in table 2

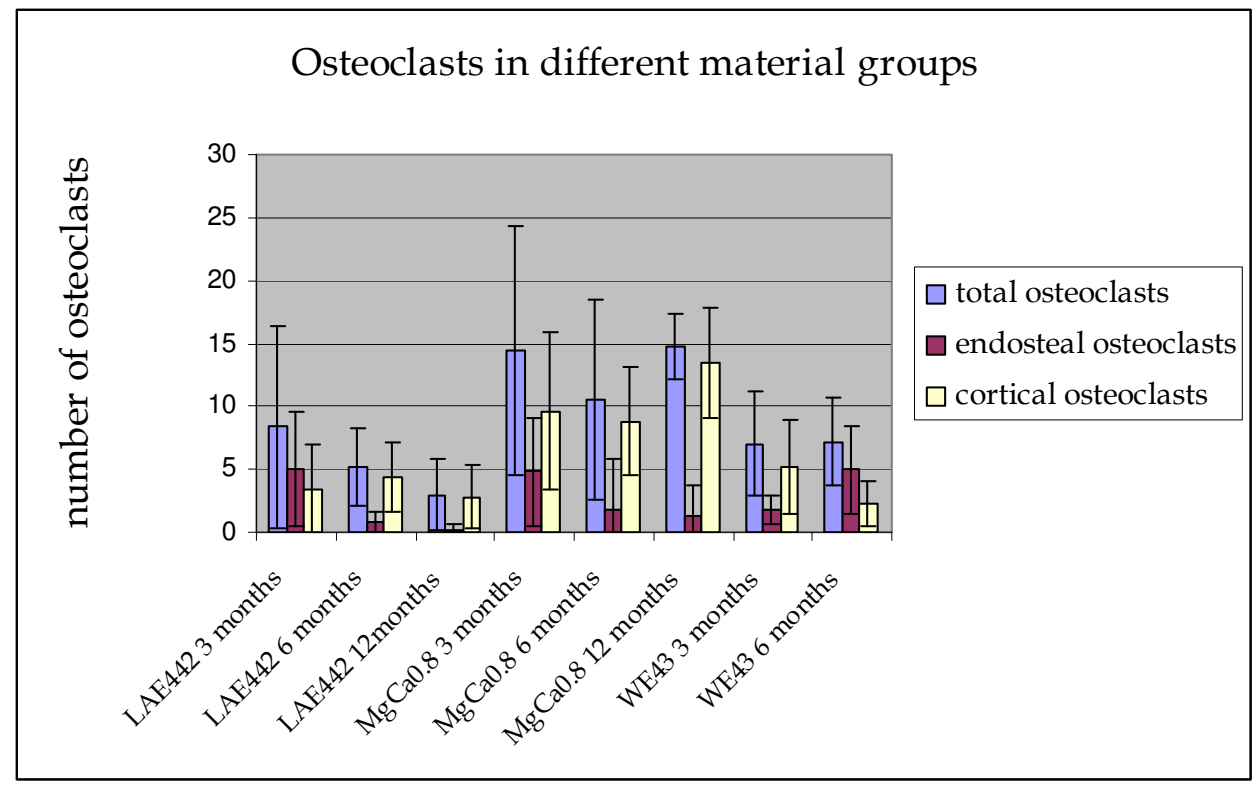

Fig. 9. Osteoclasts in different material groups after 3, 6 and in MgCa0.8 and LAE442 12 months of implantation duration.

\section{Discussion}

The purpose of all described studies was to investigate the applicability of different magnesium alloys as biodegradable materials in osteosynthesis. Beside an adequate primary mechanical stability and the ability to degrade without side effects, a good biocompatibility is required.

Magnesium itself is described as relatively safe and assessed as non-toxic (Staiger et al., 2006). It is an essential element for the human body and fulfils many functions in the 
organism. More than 300 enzymatic reactions are triggered with magnesium as part of enzymes or coenzymes and it is essential for the neuromuscular transmittance of stimuli (Topf \& Murray, 2003). About 50\% of the human body-magnesium is stored in the bone. Other reservoirs for magnesium are the muscle and inner organs, especially the liver. Only about $1 \%$ is in the blood plasma. The body-magnesium is regulated by renal excretion.

Since pure magnesium corrodes much too fast in vitro (Pardo et al., 2008) and in vivo (Huang et al., 2007) alloying of elements is necessary to slow down the degradation process. A lot of studies describe in vitro corrosion properties and characteristics of magnesium alloys in synthetic medium as $\mathrm{NaCl}$, Hank's solution or SBF (Müller et al., 2007; Pardo et al., 2008; Xu et al., 2008; Hänzi et al., 2009; Gu \& Zheng, 2010) and biocompatibility in cell culture (Xu et al., 2009). Unfortunately, until now, there is no in vitro method, which can predict the in vivo corrosion characteristics and in vitro and in vivo results can differ gravely (Witte et al., 2006; Gu \& Zheng, 2010; Zhang et al. 2010). Therefor in vivo studies are essential to investigate in vivo corrosion and biocompatibility. Only few different magnesium alloys have been examined in vivo yet (Tab. 4). In our studies additionally to earlier described magnesium alloys WE43, LAE442 and MgCa0.8, the magnesium alloys ZEK100 and AX30 were investigated, which consisted of different alloying elements to optimize the characteristics of magnesium itself. Aluminium, as alloying element in AX30 and LAE442 is known to diminish the corrosion rate by stabilizing hydroxides in chloride environment. It is reported, that the corrosion rate decreases rapidly with increasing aluminium up to $4 \%$, further additions up to $9 \%$ give only a modest further improvement (Song \& Atrens, 1999). AZ31 and AZ91 are other aluminium containing alloys which are often used materials in in vitro (Müller et al., 2007; Witte et al., 2006) and in vivo studies (Witte et al., 2005; Huang et al., 2005), but the in vivo corrosion process is too fast, with a clinically observable gas production (Witte et al., 2005; Witte et al., 2007b) and the mechanical stability is not satisfactory for the use as weight bearing material ( $\mathrm{Gu}$ et al., 2010). Although Witte et al. did not find any negative influence of corroding material on the surrounding bone (Witte et al., 2007b), toxic effects of high amounts of corroding aluminium especially in osteosynthesis systems, like intramedullary nailing or plates and screws, with high amounts of metallic material, can not be excluded (Yuen et al., 2010).

Lithium, as alloying element in LAE442, is known to alkalize the corrosion layer and therefore stabilize it (Wang, 1997). This element is used therapeutically in manic-depressive psychosis with a daily clinical uptake of lithium-carbonate up to $1300 \mathrm{mg}$ (Grandjean \& Aubry, 2009a). In these therapeutic cases, negative effects like gastrointestinal pain or discomfort, renal involvement with reduced urinary concentration capacity, expressed as polyuria, as well as negative effects on memory, vigilance and reaction time are observed (Grandjean \& Aubry, 2009b). Another study with rats could even find a potential of lithium to reduce aluminium-induced cytotoxic effects in the brain (Bhalla et al., 2010). The dissolving elements from LAE442 can reach only a fraction of therapeutically used dosages. Witte et al. (2009) calculated a corrosion rate of $0.58 \mathrm{~mm} / \mathrm{y}$ in the first two postoperative weeks, which decreased during longer observation periods. Therefor a general toxic effect of lithium is very unlikely. Whether marginal lithium concentrations can have direct effects on the surrounding bone is not described yet.

Calcium, as alloying element in $\mathrm{MgCa} 0.8$ and $\mathrm{AX30}$, increases the corrosion resistance already in low concentrations ( $\mathrm{Li}$ et al., 2008). It is an essential element in the human body and naturally belongs to the bone (Kannan \& Ramann, 2008). 
Zinc, as alloying element in ZEK100, can increase the tolerance limits in the magnesium alloys and reduce the effect of impurities on corrosion processes once the tolerance limit has been exceeded. Zinc overdoses can reduce the erythrocyte superoxide dismutase level, but the tolerable exposure level is with $0.83 \mathrm{mg} \mathrm{kg} \mathrm{bw}^{-1} \mathrm{day}^{-1}$ (Yuen \& Ip, 2010) and with $1 \mathrm{wt} \%$ in the ZEK100 alloy unlikely to reach.

Zirconium in magnesium alloys is used to form complexes with zinc and certain elements which are impurities (Avedesian \& Baker, 1999) to improve the corrosion resistance. The daily human uptake has been known to be as high as $125 \mathrm{mg}$, toxic effects induced by very high concentrations are non-specific in nature (Ghosh et al., 1992). Negative effects on the circumjacent bone are not described (Lit). In magnesium alloys, an exposure limit for zirconium is not known yet (Yuen \& Ip, 2010).

Rare Earth metals as alloying elements in LAE442, WE43 and ZEK100 reduce the corrosion resistance by forming solid solutions or intermetallic compounds, a rare earth enrichment in the oxide film and possibly a formation of an additional magnesium hydride layer. Therefor they have beneficial effects on the castability, improve the tensile and creep properties as well as the corrosion resistance (Nakatsugawa et al., 1998). In the human body, chelated rare earths are rapidly excreted via urine, while unchelated ionic rare earths easily form colloid in blood and the colloid material is taken up by phagocytic cells of the liver and spleen. An other target organ of the rare earths is the bone, but is it not clear, what cells of the bone take up the most rare earths. The clearance of the bone is known to be very slow, but the general potential toxicity is described to be low (Hirano \& Suzuki, 1996).

Beneath to different alloying elements, the surface treatment can have an effect on in vivo corrosion properties as well. Von der Höh et al. (Von der Höh et al., 2006) showed, that MgCa0.8 alloys with sand-blasted surface machining treatment had a higher corrosion rate in vivo than implants with a smooth surface. Witte el al. used a fluoride coating to reduce the in vivo corrosion rate of LAE442 (Witte et al., 2009). These results are in contrast to the results of Thomann et al., who could not find a reduction of the corrosion rate in MgCa0.8implants with fluoride coating although the fluoride layer could be detected at the end of the implantation period of six months (Thomann et al., 2010).

Based on slow degradation rates of the used alloys, toxic effects were not expected in the present studies. All implant materials used showed no clinically and radiographically observable gas generation. Even the degradation celerity in the faster degrading alloys was apparently slow enough for the body to remove the emerging gas during the corrosion process. After six months implantation duration the cylinders of all groups still existed, even all implant materials showed obvious signs of corrosion, which were different between the alloys. MgCa0.8 and WE43 degraded to a greater extend than the other materials Ax30, ZEK100 and LAE442. Especially LAE442 showed a very uniform and slow degradation process even after an observation period of 12 months. This slow degradation process of LAE442 was confirmed in other studies (Witte et al., 2009). The reactions of the bone could be used to evaluate the biocompatibility (Sumner-Smith \& Fackelmann, 2002). After observation periods of six and twelve months, the majority of the $\mu$-computed tomography slices of all alloys showed new endosteally based bone formation which increased in the two groups with longer observation periods (MgCa0.8 and LAE442). After 12 months the boneimplant contact with mostly trabecular bone formation was clearly stronger in the MgCa 0.8 group, although the degradation had progressed further. On the one hand a possible explanation for this divergence could be the $9 \%$ higher magnesium amount of the $\mathrm{MgCa} 0.8$ implants. On the other hand the calcium content could enhance the formation of precipitates 
of calcium and phosphorous in the implant periphery which is discussed as a possible mineralization source (Lu \& Leng, 2005).

With the intravital fluorescence labelling, increased bone remodelling activity of the magnesium alloys MgCa0.8 and LAE442 during an observation period of six months in comparison to the control group could be observed, which confirmed the observations in

\section{in-vivo studies of magnesium alloys for orthopedic research}

\begin{tabular}{|c|c|c|c|c|c|c|c|}
\hline Mg-alloy & coating & $\begin{array}{l}\text { animal } \\
\text { model }\end{array}$ & $\begin{array}{l}\text { implant } \\
\text { location }\end{array}$ & observation time & $\begin{array}{l}\text { gas } \\
\text { formation }\end{array}$ & author & year \\
\hline \multicolumn{8}{|l|}{ LAE442 } \\
\hline LAE442 & no & rabbit & tibia & 3 and 6 months & no & Krause et al. & 2010 \\
\hline LAE442 & no & rabbit & tibia & 9 and 12 months & no & Thomann et al. & 2010 \\
\hline LAE442 & no/ fluoride & rabbit & femora & $2,4,6$ and 12 weeks & no & Witte et al. & 2010 \\
\hline LAE442 & no & guinea pig & femora & 18 weeks & yes & Witte et al. & 2005 \\
\hline \multicolumn{8}{|l|}{$\mathrm{MgCa}$} \\
\hline $\mathrm{MgCa} 0.8$ & no & rabbit & tibia & 3 and 6 months & no & Krause et al. & 2010 \\
\hline $\mathrm{MgCa} 0.8$ & no & rabbit & tibia & 9 and 12 months & no & Thomann et al. & $2010 \mathrm{a}$ \\
\hline $\mathrm{MgCa} 0.8$ & fluoride & rabbit & tibia & 3 and 6 months & no & Thomann et al. & $2010 b$ \\
\hline $\mathrm{MgCa} 0.2-2.0$ & no & rabbit & femora & & some & Von der Höh et al. & 2008 \\
\hline $\mathrm{MgCa} 1.0$ & no & rabbit & femora & 1,2 and 3 months & yes & Li et al. & 2008 \\
\hline \multicolumn{8}{|l|}{$\mathrm{AZ}$} \\
\hline AZ91/AZ31 & no & guinea pig & femora & 18 weeks & yes & Witte et al. & 2005 \\
\hline AZ91 & no & rabbit & femora & 3 and 6 months & yes & Witte et al. & $2007 a / b$ \\
\hline AZ31 & no & rabbit & femora & 1 and 9 weeks & & $\begin{array}{l}\text { Huang et al. / Ren } \\
\text { et al. }\end{array}$ & 2007 \\
\hline \multicolumn{8}{|l|}{ WE } \\
\hline WE43 & no & rabbit & tibia & & no & Krause et al. & 2010 \\
\hline WE43 & no & guinea pig & femora & 18 weeks & & Witte et al. & 2005 \\
\hline \multicolumn{8}{|l|}{ MgZnMn } \\
\hline MgZn1Mn1.2 & no & rat & femora & 9 and 18 weeks & & Xu et al. & 2007 \\
\hline MgMn1Zn0.8 & no & rat & femora & 6,10 and 26 weeks & & Zhang et al. & 2008 \\
\hline MgMn1.2Zn1.0 & no/ Ca-P & rabbit & femora & $1,2,3$ and 4 weeks & & Xu et al. & 2009 \\
\hline \multicolumn{8}{|l|}{ MgZn } \\
\hline MgZn6 & no & rabbit & femora & 6 and 18 weeks & yes & Zhang et al. & 2008 \\
\hline \multicolumn{8}{|l|}{$\mathrm{MgZnCa}$} \\
\hline $\begin{array}{l}\operatorname{MgZn} 20 / 23 / 29 \\
/ 35 \mathrm{Ca} 5\end{array}$ & no & pig & $\begin{array}{l}\text { abdominal } \\
\text { cavity/-wall }\end{array}$ & 27 and 91 days & some & Zberg et al. & 2009 \\
\hline \multicolumn{8}{|l|}{ ZEK } \\
\hline ZEK100 & no & rabbit & tibia & 3 and six months & no & present results & \\
\hline \multicolumn{8}{|l|}{$\mathrm{AX}$} \\
\hline AX30 & no & rabbit & tibia & 3 and six months & no & present results & \\
\hline
\end{tabular}

Table 4 . In vivo-studies of different magnesium alloys in different animal models and with different time periods 
the $\mu$-computed tomography. In both examined groups, the mineral apposition rate as sign for bone remodelling activity (Parfitt et al., 1987) was highest in the first time period (between the third and the 33th postoperative day), and even higher in the MgCa0.8 group in comparison to the LAE442-group, which was seen in the $\mu$-computed tomography as well. A decreased MAR around magnesium scaffolds was also found in other studies (Witte et al., 2007b). In both groups of our studies the MAR showed a decrease during postoperative time and from three to six months only marginal differences in comparison to the control, although the MAR in the $\mathrm{MgCa} 0.8$ group remained little higher than in the control group and the LAE442 group. The number of osteoclasts, as a sign for bone remodelling activity, which was counted in the TRAP-stained sections, confirmed these results but showed increased bone remodelling activity in the group with $\mathrm{MgCa} 0.8$ alloys even after twelve months implantation duration. The number of osteoclasts in the LAE442 group decreased over time albeit no significances could be found. The increased bone remodelling could be indicative of magnesium alloy induced osteoinductive properties These osteoinductive properties are supposed by other authors as well ( $\mathrm{Li}$ et al., 2008; $\mathrm{Xu}$ et al., 2007; Witte et al., 2007b). As possible reason for the observed osteoinductive effects, $\mathrm{Xu}$ et al. summarized the degradation process of magnesium alloy implants as following: just after implantation, the surface of magnesium implants will react in the body fluids and the magnesium alloy will start to dissolve. With the increasing concentration of magnesium ions, a magnesium-containing calcium phosphate will precipitate from the body fluid on the surface of the magnesium implant, per following reaction:

$$
\mathrm{Mg}^{2+}+\mathrm{Ca}^{2+}+\mathrm{HPO}_{4}^{-} \rightarrow \mathrm{Mg}_{\mathrm{x}} \mathrm{Ca}_{\mathrm{y}}\left(\mathrm{PO}_{4}\right)_{\mathrm{z}}
$$

The high $\mathrm{Ca}^{2+}$ and $\mathrm{Mg}^{2+}$ contents in this degradation layer in turn accelerate the deposition of biological calcium phosphate on the surface and thereby induce the formation of new bone (Xu et al., 2007). A further explanation for the enhanced bone remodeling activity is the regenerating effect of magnesium ions on alkaline phosphatase activity (Bonucci et al., 1992), which is directly related to the mineralization of the osteoid matrix (Roach, 1999). A higher bone volume per tissue volume around degrading magnesium implants and a more mature bone structure in comparison to a control group was described in other studies as well (Witte et al., 2007b; Xu et al., 2009).

Besides the biocompatibility, the tensile strength is regarded to be the critical mechanical characteristic of an implant that is supposed to be used as implant material in weight bearing bones and to stabilize bone fragments (McKibbin, 1978), while its ductility is of less importance (Hort et al., 2009, Krause et al. 2010). As it is known and even found in the described studies, magnesium alloys have a tendency for pitting corrosion (Song et al., 2005). These pits reduce the mechanical stability of the implant because they locally decrease the cross sectional diameter. As the calcium containing alloys have lower mechanical stabilities as shown in the described studies, for the use as implant material in weight bearing bones, the rare earth containing alloys should be preferred for these indications. All rare earth containing alloys had similar initial tensile strengths, LAE442 with $255.67 \mathrm{~N}$ even the highest. After 6 months, ZEK showed $41 \%$, LAE442 and WE43 still more than $50 \%$ of their initial tensile strength. Therefor the mechanical characteristics appear suitable for the application as materials for biodegradable implants in weight bearing bones. After six months, LAE442 therefor showed a very good biocompatibility even during observation periods of 12 months, with a smooth overall impression of the bone structure, which was seen in no other material group. 
It can be concluded, that magnesium alloys are very promising implant materials for orthopaedic research. Especially the rare-earth containing alloys have favourable mechanical characteristics and in particular LAE442 shows a very slow a homogeneous in vivo degradation with favourable biocompatibility even after observation periods of 12 months.

\section{References}

[1] Avedesian, M. M. \& Baker, H. (1999), Magnesium and magnesium alloys, Metallographic and Fractographic Techniques and Microstructures, ASM International. Handbook Committee, 26-35

[2] Bhalla, P.; Singla, N. \& Dhawan, D.K. (2010), Potential of lithium to reduce aluminiuminduced cycotoxic effects in rat brain, Biometals, 23, 2, 197-206

[3] Bonucci, E.; Silvestrini, G. \& Bianco, P. (1992), Extracellular alkaline phosphatase activity in mineralizing matrices of cartilage and bone: Ultrastructural localization using cerium-based method, Histochemistry, 97, 323-327

[4] Donert, K. \& Breuner, G. (1982), A method for the study of undecalcified bones and teeth with attached soft tissues. The Säge-Schliff (sawing and grinding) technique, J. Oral Patho.l, 11, 318-326

[5] Ghosh, S.; Sharma, A. \& Talukder, G. (1992), Zirconium. An abnormal trace element in biology, Biol. Trace Elem. Res., 35, 3, 247-271

[6] Grandjean, E. M. \& Aubry, J.M (2009a), Lithium: updated human knowledge using an evidence-based approach. Part II: Clinical pharmacology and therapeutic monitoring, CNS Drugs, 23, 4, 331-349

[7] Grandjean, E. M. \& Aubry, J.M. (2009b), Lithium: updated human knowledge using an evidence-based approach. Part III: clinical safety, CNS Drugs, 23, 5, 397-418

[8] Gu, X.; Zheng, Y.; Cheng, Y.; Zhong, S. \& Xi, T. (2009), In vitro corrosion and biocompatibility of binary magnesium alloys, Biomaterials, 30, 4, 484-498

[9] Gu, X. \& Zheng, F. (2010), A review on magnesium alloys as biodegradable materials, Front. Mater. Sci. China, 4, 2, 111-115

[10] Gu, X.; Zhou, W. R.; Zheng, Y. F.; Cheng, Y.; Wei, S. C.; Zhong, S. P.; Xi, T. F. \& Chen, L. J. (2010), Corrosion fatigue behaviour of two biomedical Mg alloys - AZ91D and WE43 - In simulated body fluid, Acta Biomater., doi:10.1016/j.actabio.2010.07.026

[11] Hänzi, A. C.; Gunde, P.; Schinhammer, M. \& Ugguwitzer, P. J. (2008), On the biodegradation performance of an Mg-Y-RE alloy with various surface conditions in simulated body fluid, Acta Biomater., 5, 162-171

[12] Hartwig, A. (2001), Role of magnesium in genomic stability, Mutation research, 475, 113121

[13] Hirano, S. \& Suzuki , K. T. (1996), Exposure, Metabolism, and Toxicity of Rare Earths and Related compounds, Environ Health Perspect., 104, Suppl. 1, 85-95

[14] Hofmann G. (1995), Biodegradable implants in traumatology: a rewiew on the state-ofthe-art, Arch. Orthop. Trauma Surg., 114, 123-132

[15] Hort, N.; Huang, Y.; Fechner, D.; Störmer, M.; Blawert, C.; Witte, F.; Vogt, C.; Drücker, H.; Willumeit, R.; Kainer, K. U. \& Feyerabend, F. (2009), Magnesium alloys as implant materials - Principles of property design for Mg-RE alloys, Acta Biomater., $5,1,1-13$ 
[16] Huang J.; Ren, Y.; Jiang, Y.; Zhang, B. \& Yang, K. (2007), In vivo study of degradable magnesium and magnesium alloy as bone implant, Front. Mater. Sci. China, 1, 4, 405-409

[17] Kaese, V. (2002), Beitrag zum korrosionsschützenden Legieren von Magnesiumwerkstoffen, Fortschrittberichte VDI, 5, Nr. 666

[18] Li, Z; Gu, X.; Lou, S. \& Zhang, Y. (2008), The development of binary Mg-Ca alloys for use as biodegradable materials within bone, Biomaterials, 29, 1329-1344

[19] McKibbin, B. (1978),The Biology of Fracture Healing in Long Bones, J. Bone Joint Surg., $60,2,150-162$

[20] Müller, W.D.; Nascimento, M. L.; Zeddies, M.; Corsico, M.; Gassa, L. M. \& Lorenzo de Mele, M. A. F. (2007), Magnesium and its alloys as degradable biomaterials. Corrosion studies using potentiodynamic and EIS electrochemical techniques, Mater. Res., 10, 1, 5-10

[21] Pardo, A.; Merino, M. C.; Coy, A. E.; Arrabal, R.; Viejo, F. \& Matykina, E. (2007), Corrosion behaviour of magnesium/ aluminium alloys in $3.5 \mathrm{wt} . \% \mathrm{NaCl}$, Corr. Sci., $50,3,823-834$

[22] Parfitt, A. M.; Drezner, M. K.; Glorieux, F. H.; Kanis, J. A.;Malluche, H.; Meunier, P. J.; Ott, S. M. \& Recker, R. R. (1987), Bone Histomorphometry: Standarization of Nomenclature, Symbols and Units, J. .Bone Miner. Res., 2, 6, 595-610

[23] Pearce, A.; Richards, R. G.; Milz, S.; Schneider, E. \& Pearce, S. G. (2007), Animal models for implant biomaterial research in bone: a review, European Cells and Materials, 13, $1-10$

[24] Rahn, B. A.; Bacellar, F. C.; Tarapp, L. \& Perren, S. M. (1980), Aktuelle Traumatologie, 10, 2, 109-115

[25] Revell, P. A. (2004), The effect of magnesium ions on bone bonding to hydroxyapatite. Key. Eng. Mater., 254-256, 447-450

[26] Roach, H. I. (1999), Association of matrix acid and alkaline phosphatases with mineralization of cartilage and anchondral bone, Histochem. J., 31, 53-61

[27] Sumner-Smith, G. \& Fackelmann, G. E. (2002), Bone in clinical orthopedics, $2^{\text {nd }}$ ed., Thieme, ISBN 9783131257215 Stuttgart

[28] Staiger, M. P.; Pietak, A. M.; Huadmai, J. \& Dias, G. (2006), Magnesium and its alloys as orthopedic biomaterials: a review. Biomaterials, 27, 1728-1734

[29] Thomann, M.; Krause, C.; Bormann, D.; Von der Höh, N.; Windhagen, H. \& MeyerLindenberg, A. (2009), Comparison of the resorbable magnesium alloy LAE442 an $\mathrm{MgCa} 0,8$ concerning their mechanical properties, gradient degradation and bone implant-contact after 12 month implantation in rabbit model, Materialwissenschaft und Werkstofftechnik, 40, 1-2, 82-88

[30] Thomann, M.; Krause, C.; Angrisani, N.; Bormann, D.; Hassel, T.; Windhagen, H. \& Meyer-Lindenberg, A. (2010), Influence of a magnesium-fluoride coating of magnesium-based implants (MgCa0.8) on degradation in a rabbit model, J. Biomed. Mat. Res. A, 93, 4, 1609-1619

[31] Topf, J. \& Murray, P. (2003), Hypomagnesemia and Hypermagnesemia, Rev. Endocr. Metab. Disord., 4, 195-206

[32] Von der Höh, N.; Krause, A.; Hackenbroich, C.; Bormann, D.; Lukas, A. \& MeyerLindenberg, A. (2006), Influence of different surface machining treatments of resorbable implants made from different magnesium-calcium alloys on their 
degradation- a pilot study in a rabbit models, Dtsch. tierärztl. Wochenschr., 113, 439446

[33] Wang Y. (1997), Beitrag zur Verbesserung korrosiver Eigenschaften von superleichten Magnesium-Lithium-Basislegierungen, VDI-Verlag, Düsseldorf,

[34] Witte F.; Kaese, V.; Haferkamp, H.; Switzer, E.; Meyer-Lindenberg, A.; Wirth, C. J.; Windhagen, H. (2005), In vivo corrosion of four magnesium alloys and the assotiated bone response, Biomaterials, 26, 3557-3563

[35] Witte F.; Fischer, J.; Nellesen, J.; Crostack, H. A.; Kaese, V.; Pisch, A.; Beckmann, F.; Windhagen, H. (2006) In vitro and in vivo corrosion measurements of magnesium alloys, Biomaterials 27, 7, 1013-1018

[36] Witte, F.; Abeln, I.; Switzer, E.; Kaese, V.; Meyer-Lindenberg, A.; Windhagen, H. (2007a), Evaluation of the skin sensitizing potential of biodegradable magnesium alloys, J. Biomed. Mater. Res. A, 86, 4, 1041-1047

[37] Witte, F.; Ulrich, H.; Palm, C.; Willbold, E. (2007b), Biodegradable magnesium scaffolds: Part II: Peri-implant bone remodeling, J. Biomed. Mater. Res. A, 81, 3, 757-765

[38] Xu, L.; Zhang, E.; Yin, D.; Zeng, S.; Yang, K. (2008), In vitro corrosion behaviour of Mg alloys in a phosphate buffered solution for bone implant application. J. Mater. Sci. Mater. Med., 19, 3, 1017-1025

[39] Xu, L.; Pan, F.; Yu, G.; Yang, L.; Zhang, E.; Yang, K. (2009), In vitro and in vivo evaluation of the surface bioactivity of calcium phosphate coated magnesium alloy, Biomaterials, 30, 1512-1532

[40] Yuen, C. K.; Ip, W. Y. (2010), Theoretical risk assessment of magnesium alloys as degradable biomedical implants, Acta Biomat., doi:10.1016/j.actbio.2009.11.036

[41] Zhang, S.; Zhang, X.; Zhao, C.; Li, J.; Song, Y.; Xie, C.; Tao, H.; Zhang, Y; He, Y.; Jiang, Y.\& Bian, Y. (2010), Research on a Mg-Zn alloy as a degradable biomaterial, Acta Biomater., 6, 262-640

[42] Zreiqat, H.; Howlett, C. R.; Zannettino, A.; Evans, P.; Schulze-Tanzil, G.; Knabe, C.; Shakibaei, M. (2002), Mechanisms of magnesium-stimulated adhesion of osteoblastic cells to commonly used orthopaedic implants, J. Biomed. Mater. Res., 62, 175-184 


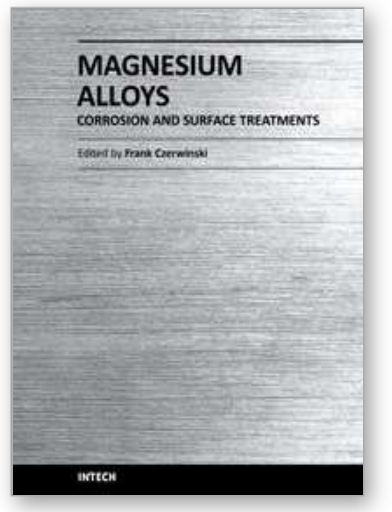

\author{
Magnesium Alloys - Corrosion and Surface Treatments \\ Edited by Frank Czerwinski
}

ISBN 978-953-307-972-1

Hard cover, 344 pages

Publisher InTech

Published online 14, January, 2011

Published in print edition January, 2011

A resistance of magnesium alloys to surface degradation is paramount for their applications in automotive, aerospace, consumer electronics and general-purpose markets. An emphasis of this book is on oxidation, corrosion and surface modifications, designed to enhance the alloy surface stability. It covers a nature of oxides grown at elevated temperatures and oxidation characteristics of selected alloys along with elements of general and electrochemical corrosion. Medical applications are considered that explore bio-compatibility of magnesium alloys. Also techniques of surface modifications, designed to improve not only corrosion resistance but also corrosion fatigue, wear and other behaviors, are described. The book represents a valuable resource for scientists and engineers from academia and industry.

\title{
How to reference
}

In order to correctly reference this scholarly work, feel free to copy and paste the following:

Janin Reifenrath, Dirk Bormann and Andrea Meyer-Lindenberg (2011). Magnesium Alloys as Promising Degradable Implant Materials in Orthopaedic Research, Magnesium Alloys - Corrosion and Surface Treatments, Frank Czerwinski (Ed.), ISBN: 978-953-307-972-1, InTech, Available from: http://www.intechopen.com/books/magnesium-alloys-corrosion-and-surface-treatments/magnesium-alloys-aspromising-degradable-implant-materials-in-orthopaedic-research

\section{INTECH}

open science | open minds

\author{
InTech Europe \\ University Campus STeP Ri \\ Slavka Krautzeka 83/A \\ 51000 Rijeka, Croatia \\ Phone: +385 (51) 770447 \\ Fax: +385 (51) 686166 \\ www.intechopen.com
}

\author{
InTech China \\ Unit 405, Office Block, Hotel Equatorial Shanghai \\ No.65, Yan An Road (West), Shanghai, 200040, China \\ 中国上海市延安西路65号上海国际贵都大饭店办公楼 405 单元 \\ Phone: +86-21-62489820 \\ Fax: +86-21-62489821
}


(C) 2011 The Author(s). Licensee IntechOpen. This chapter is distributed under the terms of the Creative Commons Attribution-NonCommercialShareAlike-3.0 License, which permits use, distribution and reproduction for non-commercial purposes, provided the original is properly cited and derivative works building on this content are distributed under the same license. 